Georgia State University

ScholarWorks @ Georgia State University

\title{
Psychological flexibility and self-concealment as predictors of disordered eating symptoms.
}

Akihiko Masuda

Georgia State University, amasuda@gsu.edu

Robert D. Latzman

Georgia State University, rlatzman@gsu.edu

Follow this and additional works at: https://scholarworks.gsu.edu/psych_facpub

Part of the Psychology Commons

\section{Recommended Citation}

Masuda, Akihiko and Latzman, Robert D., "Psychological flexibility and self-concealment as predictors of disordered eating symptoms." (2012). Psychology Faculty Publications. 90.

https://scholarworks.gsu.edu/psych_facpub/90

This Article is brought to you for free and open access by the Department of Psychology at ScholarWorks @ Georgia State University. It has been accepted for inclusion in Psychology Faculty Publications by an authorized administrator of ScholarWorks @ Georgia State University. For more information, please contact scholarworks@gsu.edu. 
Psychological Flexibility and Self-Concealment as Predictors of Disordered Eating Symptoms

Akihiko Masuda and Robert D. Latzman

Georgia State University

\author{
Author Note \\ Akihiko Masuda and Robert Latzman Department of Psychology, Georgia State \\ University \\ Correspondence regarding this article should be addressed to Aki Masuda, \\ Department of Psychology, Georgia State University, Atlanta, GA 30303, USA. Email \\ Address: amasuda@gsu.edu
}




\begin{abstract}
The present cross-sectional study investigated whether self-concealment and psychological flexibility were uniquely associated with different facets of disordered eating (DE; i.e., dieting, bulimia/food preoccupation, and oral control) and whether these associations varied across gender. Participants included 621 female and 212 male college students, ages 18-24 years old. After controlling for age, ethnicity, and BMI, both selfconcealment and psychological flexibility were uniquely related to dieting. Controlling for these demographic variables, psychological flexibility, but not self-concealment, was uniquely associated with bulimia/food preoccupation. Neither self-concealment nor psychological flexibility was uniquely associated with oral control. Finally, gender moderated the association between self-concealment and dieting, suggesting that selfconcealment was relevant to dieting in the female group, but not in the male group. Limitations of the study and future directions are discussed.
\end{abstract}

Key Words: Psychological Flexibility, Disordered Eating, Self-Concealment. 
Psychological Flexibility and Self-Concealment as Predictors of Disordered Eating

\section{Symptoms}

Disordered eating (DE) is multifaceted (Fairburn, Cooper, \& Shafran, 2003; Garner, Olmsted, Bohr, \& Garfinkel, 1982) and pervasive among adolescents and young adults in the United States (Striegel-Moore \& Bulik, 2007; Vohs, Heatherton, \& Herrin, 2001). Although only a small number of these individuals meet diagnostic criteria for an eating disorder (Hudson, Hiripi, Pope, \& Kessler, 2007), many endorse some facets of DE, such as dieting, negative body image, and compensatory behaviors (e.g., excessive exercise, purging, laxative use; Mintz \& Betz, 1988). Research also shows that DE is pervasive across gender (Lavender \& Anderson, 2010; Striegel-Moore \& Bulik, 2007) and ethnic background (Mintz \& Kashubeck, 1999; Rogers Wood \& Petrie, 2010).

Many factors are theorized to contribute to the onset and maintenance of DE (Fairburn et al., 2003; Striegel-Moore \& Bulik, 2007). One such factor that has been of great interest in recent years is emotion/behavior regulation (Aldao \& Nolen-Hoeksema, 2010; Gross, 2002; Hayes, Luoma, Bond, Masuda, \& Lillis, 2006). The construct of emotion/behavior regulation parallels a recent focus in cognitive behavioral therapy (CBT) models of psychopathology. These models suggest that diverse forms of psychopathology, including DE, are attributable not only to the presence of negative internal experiences (e.g., emotion, cognition, and bodily sensation), but also to how one responds to or relates to them. Emotion/behavior regulation abilities can be roughly defined as the processes by which individuals influence the psychological experiences they have, and how emotions are experienced and expressed accordingly (Gross, 1998; Rawal, Park, \& Williams, 2010). Maladaptive regulation processes, such as, rumination, experiential avoidance, and thought 
suppression, are found to be associated with a broad range of distress, including DE (Aldao \& Nolen-Hoeksema, 2010; Aldao, Nolen-Hoeksema, \& Schweizer, 2010; Rawal et al., 2010).

\section{Self-Concealment}

Self-concealment reflects an underlying maladaptive regulation process in diverse clinical phenomena, including DE. Self-concealment is construed as a general and stable behavioral tendency to keep distressing and potentially embarrassing personal information from others. This behavioral pattern involves the processes of (a) possessing a negatively evaluated secret, (b) keeping it from others, and (c) avoiding or feeling apprehensive about self-disclosure (Larson \& Chastain, 1990). Extant literature has reported that individuals who endorse DE tend to distort or withhold personal information, such as their problematic eating, drive for thinness, and negative body image (Pryor, Johnson, Wiederman, \& Boswell, 1995; Vandereycken \& Van Humbeeck, 2008). Research has also shown that selfconcealment is in fact positively associated with general DE symptoms (i.e., diet, bulimia/food preoccupation, and oral control combined) and DE cognitions (Masuda, Boone, \& Timko, 2011).

\section{Diminished Psychological Flexibility}

Another behavioral process that has been widely studied in recent years is psychological flexibility (Hayes et al., 2006; Hayes, Villatte, Levin, \& Hildebrandt, 2011). The construct of psychological flexibility is derived from an acceptance- and mindfulnessbased CBT, Acceptance and Commitment Therapy (ACT; Hayes, Strosahl, \& Wilson, 2012). ACT emphasizes open and flexible ways of experiencing internal and external environments to promote greater vital living. Psychological flexibility is conceptualized as 
a process of (a) experiencing the present moment as it is without judgment and avoidance and (b) persisting or changing behavior when doing so serves valued-ends (Hayes et al., 2006). According to an ACT theory, greater psychological flexibility is theorized to be a cornerstone of behavioral health (Kashdan \& Rottenberg, 2010). Conversely, many forms of psychopathology are marked by diminished psychological flexibility, which reflects the domination of maladaptive affect/behavior regulations (e.g., thought suppression and avoidance) and the deficits of contingency-sensitive and value-directed behaviors. Indeed, a growing body of evidence has demonstrated diminished psychological flexiblity is associated with a wide range of behavioral problems (Hayes et al., 2006), including general DE problems (Masuda, Price, \& Latzman, 2012; Rawal et al., 2010).

\section{Self-Concealment and Psychological Flexibility as Predictors of Disordered Eating}

Preliminary findings with non-clinical college samples suggest that selfconcealment and psychological flexibility are related but distinct processes uniquely and separately associated with a range of psychological distress (Masuda, Anderson, \& Sheehan, 2009; Masuda, Anderson, et al., 2011), including DE (Masuda, Boone, et al., 2011). In regards to the associations among self-concealment, psychological flexibility, and DE symptoms, several questions still remained unanswered. First, as DE is multifaceted (Garner et al., 1982), it is important to investigate whether self-concealment and psychological flexibility are associated with specific aspects of DE, but not with other facets of DE. As a given form of DE symptoms may be qualitatively different from other DE symptoms (Williamson, Gleaves, \& Stewart, 2005), it is possible that the association among self-concealment, psychological flexibility, and DE may vary, depending on the type of DE symptoms (e.g., diet, bulimia/food preoccupation, and oral control). Second, 
previous studies have not examined whether the associations among self-concealment, psychological flexibility, and DE symptoms vary across gender. As gender is found to be a major predictor of DE (Striegel-Moore \& Bulik, 2007) and gender differences are found in associations between regulation process and internalizing problems (Cramer, Gallant, \& Langlois, 2005), it seems worthwhile to investigate whether gender moderates these associations. Given the pervasive nature of DE in adolescents and young adults, investigating these associations has practical value for case conceptualization and assessment, and perhaps for the treatment of DE.

\section{Present Study}

Given these emerging questions, the present study first investigated whether selfconcealment and psychological flexibility were uniquely associated with specific sets of DE symptoms (i.e., diet, bulimia/food preoccupation, and oral control). Subsequently, the study investigated whether these associations varied by gender. Given previous findings (e.g., Masuda, Boone, et al., 2011), it was predicted that, after controlling for gender, ethnicity, and BMI, both self-concealment and psychological flexibility would be related to all aspects of DE. Given the dearth of evidence, we did not make any a priori hypotheses regarding whether gender would moderate the associations between self-concealment and DE symptoms or the links between psychological flexibility and DE symptoms.

\section{Method}

\section{Participants}

The current cross-sectional study was conducted at a large, urban, public 4-year university in the Southeastern United States. Participants were recruited from undergraduate psychology courses through a web-based research survey tool. Nine hundred 
and eighty-seven participants $\left(75 \%, n_{\text {Female }}=738\right)$ completed a survey package that contained multiple self-report measures. Of those individuals, 39 participants $\left(92 \%, n_{\text {Female }}\right.$ = 36) were excluded from the study because their self-reported information of weight and height was not available to compute Body Mass Index (BMI) scores. BMI scores were calculated using the following formula, (weight (lb) / [height (in) $]^{2}$ x 703). An additional 114 individuals $\left(70 \%, n_{\text {Female }}=80\right)$ younger than 18 years old or 25 years old or older were excluded from the present study to establish a representative college sample. Finally, four participants were removed from the analysis due to the outlier analysis on BMI. The final sample consisted of 830 participants $\left(n_{\text {female }}=618 ; n_{\text {male }}=212\right)$ ages 18 to 24 years old $(M$ $=19.48, S D=1.50)$ with an average BMI of $23.57(S D=4.87)$.

The mean age of women was 19.41 years old $(S D=1.44)$. Their BMI scores ranged from 15.12 to $48.42(M=23.55, S D=5.02)$. Using the standard weight status categories; “underweight” (BMI < 18.5), “normal” (BMI between 18.5 and 24.9), “overweight” (BMI between 25 and 29.9) and “obese” (BMI > 30.0), 8\% $(n=51)$ qualified as being “underweight,” 64\% ( $n=397)$ “normal,” 18\% $(n=110)$ “overweight,” and 10\% $(n=60)$ “obese”. The female group was diverse in ethnic background with 37\% $(n=230)$ identifying as “European American,” 32\% $(n=197)$ identifying as “African American,” 15\% ( $n=93)$ identifying as “Asian American/Pacific Islander,” 6\% $(n=34)$ identifying as “Hispanic American,” 10\% ( $n=64)$ identifying as "bicultural” or "other,” and one identifying as "Native American.”

The mean age of men was 19.68 years old $(S D=1.66)$. The BMI scores ranged from 15.96 to $45.03(M=23.68, S D=4.42)$. Six percent $(n=12)$ of men fell within the underweight range, 64\% $(n=136)$ normal, 25\% $(n=52)$ overweight, and 6\% $(n=12)$ 
obese. The male group was also diverse in ethnic background with 39\% $(n=82)$ identifying as “European American,” 27\% $(n=57)$ identifying as “African American,” 21\% ( $n=45)$ identifying as “Asian American/Pacific Islander,” 5\% $(n=11)$ identifying as “Hispanic American,” 8\% $(n=16)$ identifying as "bicultural” or "other,” and one identifying as “Native American.”

\section{Measures and Procedure}

The current study was approved by the Institutional Review Board of the university. Participants completed an anonymous web-based survey. Prior to the survey, the purpose of the study and instructions for responding were presented to the participants. The following measures were administered to assess self-concealment, psychological flexibility, and DE symptoms.

Self-concealment. The Self Concealment Scale (SCS; Larson \& Chastain, 1990) is a self-report inventory designed to measure a person's tendency to conceal personal information that is distressing (e.g., "There are lots of things about me that I keep to myself”). The SCS contains 10 items and employs a 5-point Likert scale ranging from 1 (strongly disagree) to 5 (strongly agree) for each item. The total score is derived from the sum of responses to all items, with greater values indicating greater self-concealment. The SCS is a reliable measure of self-concealment, with test-retest (over 4 weeks) and interitem reliability estimates of .81 and .83, respectively (Larson \& Chastain, 1990). In the present study, Cronbach’s alpha of this measure was .88.

Psychological flexibility. The Acceptance and Action Questionnaire-16 item (AAQ-16; Bond \& Bunce, 2003) was used to measure psychological flexibility. The AAQ16 is a 16-item questionnaire designed to assess willingness to accept undesirable thoughts 
and feelings (e.g., "It is OK to feel depressed or anxious”) and acting in a way that is consistent with one’s values and goals (e.g., "I am able to take action on a problem even if I am uncertain of the right thing to do”). The measure uses a 7-point Likert scale, ranging from 1 (never true) to 7 (always true). Total scores range from 16 to 112, with higher scores indicating greater psychological flexibility. Research has indicated that the AAQ has adequate psychometric properties (Bond \& Bunce, 2003). In a previous study conducted with a non-clinical sample (Bond \& Bunce, 2003), Cronbach’s alpha for this measure ranged from .72 to .79. The Cronbach’s alpha of this measure was .62 in the present study.

Disordered eating. The 26-item version of the Eating Attitudes Test (EAT-26; Garner et al., 1982) is a self-report inventory for assessing general eating disorder pathology (e.g., “I am terrified about being overweight,” and “I vomit after I have eaten”). Each of the 26 items is scored on a 6-point Likert scale: never (0), rarely (0), sometimes (0), often (1), very often (2), or always (3). The measure also forms three subscales: (a) Dieting, (b) Bulimia and Food Preoccupation, and (c) Oral Control. The Dieting subscale consists of 13 items to detect negative body image and avoidance of fattening foods (e.g., “particularly avoid food with high carbohydrate content”). The Bulimia and Food Preoccupation subscale consists of 6 items, designed to measure obsessive thoughts toward food as well as bulimic behaviors (e.g., "have gone on eating binges where I feel that I may not be able to stop”). The Oral Control subscale, which consists of 7 items, measures food restriction and pressure felt from others to gain weight (e.g., "avoid eating when I am hungry”). Higher scores in each subscale reflect greater eating disorder pathology in the specific symptomatic domain. In the current study, Cronbach’s alphas of Dieting, Bulimia and Food Preoccupation, and Oral Control subscales were .85, 79, and .64, respectively. 


\section{Data Analysis}

In the present set of analyses, gender was dummy coded as $1=$ male and $2=$ female, and ethnicity as 1 = ethnic minority and 2 = Caucasian American. We first examined zero-order correlations among all study variables. Then hierarchical multiple regressions were used to examine how self-concealment and psychological flexibility were uniquely associated with DE outcomes and whether these associations varied by gender. Three regressions were performed in a three-step procedure. The first step included gender, ethnicity, and BMI as covariates. The second step included self-concealment and psychological flexibility. The two-way interactions of self-concealment and psychological flexibility by gender were separately entered in step three.

Preliminary analyses revealed that all DE outcomes (i.e., dieting, bulimia/food preoccupation, and oral control) were positively skewed. Additionally, $28 \%$ of men ( $n=$ $60)$ and $19 \%$ of women $(n=117)$ did not endorse any symptoms in dieting, $72 \%$ of men ( $n$ $=153)$ and $67 \%$ of women $(n=414)$ in bulimia/food preoccupation, and $31 \%$ of men $(n=$ $67)$ and $33 \%$ of women $(n=208)$ in oral control. As such, all DE outcomes were log10 transformed after adding a constant (i.e., 1); transformed data were used in all subsequent analyses. Self-concealment and psychological flexibility scores were standardized (i.e., zscored) and standardized scores were used to compute interaction terms and used for all regression analyses.

\section{Results}

\section{Associations among Study Variables}

Descriptive statistics and correlations among study variables are presented in Table 1. Self-concealment was significantly and positively associated with dieting (i.e., avoidance 
of fattening foods and a preoccupation with being thinner) and bulimia/food preoccupation (i.e., thoughts about food as well as those indicative of bulimia). Conversely, psychological flexibility was significantly and inversely related to diet and bulimia/food preoccupation. Neither self-concealment nor psychological flexibility was associated with oral control (i.e., food intake restriction and the perceived pressure from others to gain weight). There was a significant inverse association between self-concealment and psychological flexibility. BMI was positively associated with dieting and bulimia/food preoccupation and inversely related to oral control. Finally, being female was significantly associated with greater dieting and lower psychological flexibility.

\section{Role of Self-Concealment and Psychological Flexibility on DE Symptoms}

The final steps of three hierarchical regression analyses are presented in Table 2. The results of the first hierarchical regression suggested that, after controlling for the effects of gender, ethnicity, and BMI (Step $\left.1 ; R^{2}=.05, p<.01\right)$, self-concealment $(\beta=.13$, $p<.01)$ and psychological flexibility $(\beta=-.19, p<.01)$ were related to dieting (Step $2 ; R^{2}{ }_{\Delta}$ $=.07, p<.01)$. Furthermore, the association between self-concealment and dieting was found to vary by gender $\left(\beta=.36, p<.05\right.$; Step $\left.3 R^{2}{ }_{\Delta}=.01, p<.05\right)$. To examine the specific form of this significant self-concealment by gender interaction, the slope of the final equation was computed at points that corresponded to high and low levels of the predictor variables ( \pm 1.0 SD) (Aiken \& West, 1991). The positive association between self-concealment and dieting was significantly more likely in the female group than in the male group (Figure 1).

The results of the second hierarchical regression suggested that, after controlling for the effects of gender, ethnicity, and BMI (Step $1 ; R^{2}=.01, p>.05$ ), psychological 
flexibility $(\beta=-.20, p<.01)$, but not self-concealment $(\beta=.04, p>.05)$, was related to bulimia/food preoccupation (Step $2 ; R^{2}{ }_{\Delta}=.05, p<.01$ ). Gender did not moderate the association between self-concealment and bulimia/food preoccupation or the link between psychological flexibility and bulimia/food preoccupation (Step 3; $R^{2}{ }_{\Delta}=.00, p>.05$ ).

The third regression revealed that after controlling for the key demographic variables (Step $1 ; R^{2}=.02, p<.01$ ), neither self-concealment nor psychological flexibility were significantly associated with oral control (Step $2 ; R^{2}{ }_{\Delta}=.00, p>.05$ ). Furthermore, gender did not moderate the association between self-concealment and bulimia/food preoccupation or the link between psychological flexibility and bulimia/food preoccupation (Step $3 R_{\Delta}^{2}=.00, p>.05$ ). Finally, after controlling for other demographic and process variables as well as interaction terms, greater BMI was found to be associated with greater dieting, greater bulimia/food preoccupation, and lower oral control.

\section{Discussion}

The present study investigated whether self-concealment and psychological flexibility were uniquely associated with different facets of DE and whether these associations varied across gender. As expected, both self-concealment and psychological flexibility were uniquely associated with dieting after controlling for gender, ethnicity, and BMI. However, contrary to our prediction, psychological flexibility, but not selfconcealment, was uniquely associated with bulimia/food preoccupation. Furthermore, neither self-concealment nor psychological flexibility were uniquely related to oral control after controlling for these key demographic variables. Finally, gender was found to moderate the association between self-concealment and dieting; the association between the two variables was found for women, but not men. In sum, the present study has shown 
that self-concealment and psychological flexibility are relevant to some facets of DE, but not to others, and that self-concealment is a useful construct in understanding dieting in women, but not in men.

Conceptually, our findings also suggest that different facets of DE may function differently from one another and that topographically identical DE symptoms (e.g., diet) may be qualitatively and functionally distinct across gender. For example, while dieting and bulimia/food preoccupation seem to reflect rigid and avoidant patterns, oral control does not. Similarly, while dieting seems to involve secretiveness in women, dieting does not seem to be relevant to the behavioral tendency of secrecy in men. Although it is beyond the scope of the present study, the gender difference can be attributable to differential psychosocial contingencies operating across gender; while dieting is socially acceptable practice in men, behavior of dieting may be linked to negative psychosocial connotations in women, such as the signs of negative body image and feelings of insecurity.

Given previous findings (Masuda, Boone, et al., 2011), the lack of significant associations between the present process variables (i.e., self-concealment and psychological flexibility) and oral control was somewhat surprising. As mentioned above, this set of findings can be attributable to the qualitatively unique nature of oral control. In particular, contrary to other facets of DE symptoms (diet, bulimia/food preoccupation), which are likely to be negatively reinforced (Lillis, Hayes, \& Levin, 2011; Rawal et al., 2010), oral control may function differently across individuals (Mizes et al., 2000; Slade, 1982). While oral control may be negatively reinforced in some individuals, it may be positively reinforced in others. The present findings may parallel with extant literature suggesting food intake restriction, a behavior pattern captured by the construct of oral 
control, to be qualitatively distinct from other DE symptoms (dieting, binging, and purging) (Wonderlich, Joiner, Keel, Williamson, \& Crosby, 2007).

The present study also has implications for practice. Our findings suggest investigating self-concealment and psychological flexibility and their associations with different facets of DE may be useful to elucidate the functional nuances of these DE symptoms. This practical implication parallels the recent acceptance- and mindfulnessbased cognitive behavioral therapies (Hayes, Follette, \& Linehan, 2004), which target affect/behavioral regulation for the amelioration of human struggles. Preliminary evidence indicates that these treatment modalities are effective in decreasing DE and in improving psychological health (Berman, Boutelle, \& Crow, 2009; Juarascio, Forman, \& Herbert, 2010; Martín-Murcia, Díaz, \& Gonzalez, 2011; Masuda, Muto, Hayes, \& Lillis, 2008; Pearson, Follette, \& Hayes, 2011). Our study supports these treatments by elucidating a potential relevance of psychological flexibility and self-concealment to specific facets of DE symptoms across gender.

The present study had several notable limitations. First, the associations among selfconcealment, psychological flexibility, and DE symptoms, while statistically significant, were small. As such, interpreting the present findings as well as deriving conceptual and theoretical implications requires extra cautions. Our findings suggest that other factors are likely to contribute to the onset and maintenance of DE symptoms. To investigate this possibility, future studies should investigate the roles of self-concealment, psychological flexibility, and gender while controlling for other well-known correlates, such as neuroticism (Tylka \& Subich, 2004), perfectionism (Brannan \& Petrie, 2008), and body image dissatisfaction and disturbance (Stice, Hayward, Cameron, Killen, \& Taylor, 2000). 
Alternatively, the lack of associations or small associations between the process variables of interest and DE symptoms might have been due to the limited variance across DE symptoms measured by the subscales of EAT-26 to examine the present research hypotheses. As such, further study is warranted, particularly in a sample of males and females with eating disorder diagnoses.

Second, the external validity of our findings is limited as they were derived exclusively from undergraduate students attending an urban area university in the southeastern United States. As such, sociocultural factors specific to the present sample, such as religious and political climates, ethnic group compositions, and university culture, are likely to influence the variables of interest. Psychometrically, the scales used in the present study have not been fully tested and validated in individuals from diverse ethnic backgrounds. Additionally, the coefficient alphas of the AAQ-16, a measure of psychological flexibility, and the Oral Control subscale of EAT-26 were lower than a conventionally acceptable level. Future studies should employ more psychometrically sound measures of psychological inflexibility, such as the Acceptance and Action Questionnaire-II (AAQ-II) (Bond et al., 2011) and DE, such as the Eating Disorder Examination Questionnaire (EDE-Q) (Fairburn, 2008).

Finally, the most notable limitation was that the present study was a cross-sectional investigation with the exclusive reliance on self-report measures. The study did not permit any causal inferences or functional associations among the variables of interest. Given the present methodology (i.e., web-based survey study), it is unclear whether the scores, including the BMI, were subject to errors, although the anonymous nature of a web-based study might have decreased biases. From a functional and contextual perspective, the 
variables of our interest (e.g., psychological flexibility and dieting) are ongoing behavioral processes in a given context. As such, the use of behavioral observation methods, if possible, seems suitable for investigating the present research questions.

Limitations notwithstanding, the present study adds additional evidence regarding associations among self-concealment, psychological flexibility, gender, and specific facets of DE. Our findings suggest that the associations among self-concealment, psychological flexibility, and DE vary depending on gender and specific facets of DE. 
PSYCHOLOGICAL FLEXIBILITY AND DISORDRED EATING BEHAVIOR 17

Table 1

Means, Standard Deviations and Zero-Order Relations between all Variables

\begin{tabular}{lccccccc} 
& 1 & 2 & 3 & 4 & 5 & 6 & 7 \\
\hline 1. Diet & -- & & & & & & \\
2. Bulimia and Food Preoccupation & $.52^{* *}$ & - & & & & \\
3. Oral Control & $.20^{* *}$ & $.29^{* *}$ & -- & & & \\
4. Self-Concealment & $.20^{* *}$ & $.13^{* *}$ & .04 & -- & & & \\
5. Psychological Flexibility & $-.26^{* *}$ & $-.22^{* *}$ & -.02 & $-.42^{* *}$ & -- & & \\
6. Gender & $.12^{* *}$ & .02 & -.02 & -.03 & $-.10^{* *}$ & -- & \\
7. Ethnicity & .01 & -.03 & -.04 & $-.08^{*}$ & $.09^{*}$ & -.01 & -- \\
8. BMI & $.20^{* *}$ & $.08^{*}$ & $-.10^{* *}$ & -.03 & -.03 & -.01 & $-.07^{*}$ \\
& & & & & & & \\
$M$ & $5.22^{\mathrm{a}}$ & $1.19^{\mathrm{a}}$ & $2.27^{\mathrm{a}}$ & $28.95^{\mathrm{a}}$ & $70.62^{\mathrm{a}}$ & & $23.58^{\mathrm{a}}$ \\
SD & $6.24^{\mathrm{a}}$ & $2.51^{\mathrm{a}}$ & $2.87^{\mathrm{a}}$ & $8.55^{\mathrm{a}}$ & $9.06^{\mathrm{a}}$ & & $4.87^{\mathrm{a}}$ \\
& & & & & & & \\
\hline
\end{tabular}

Note: ${ }^{*} p<.05,{ }^{* *} p<.01, N=830$.

athe value was calculated based on raw data. 
PSYCHOLOGICAL FLEXIBILITY AND DISORDRED EATING BEHAVIOR 18

Table 2

Final Step of a Hierarchical Linear Regression Examining the Role of Self-Concealment, Psychological Flexibility, and Gender on Psychological Distress.

\begin{tabular}{|c|c|c|c|c|}
\hline & $b$ & & $S E$ & $\beta$ \\
\hline \multicolumn{5}{|l|}{ Diet } \\
\hline Intercept & -.03 & & .20 & \\
\hline Gender & .11 & & .03 & .11 \\
\hline Ethnicity & .05 & & .03 & .11 \\
\hline BMI & .02 & * & .00 & .19 \\
\hline Self-Concealment & -.09 & & .06 & -.22 \\
\hline Psychological Flexibility & -.05 & & .07 & -.12 \\
\hline Self-Concealment x Gender & .09 & $*$ & .04 & .36 \\
\hline Psychological Flexibility x Gender & -.02 & & .04 & -.07 \\
\hline \multicolumn{5}{|l|}{ Bulimia and Food Preoccupation } \\
\hline Intercept & .08 & & .07 & \\
\hline Gender & .00 & & .03 & .00 \\
\hline Ethnicity & .00 & & .02 & .00 \\
\hline BMI & .01 & $*$ & .00 & .07 \\
\hline Self-Concealment & -.06 & & .05 & -.20 \\
\hline Psychological Flexibility & -.10 & & .05 & -.30 \\
\hline Self-Concealment x Gender & .04 & & .03 & .25 \\
\hline Psychological Flexibility x Gender & .02 & & .03 & .11 \\
\hline \multicolumn{5}{|l|}{ Oral Control } \\
\hline Intercept & .63 & & .08 & \\
\hline Gender & -.04 & & .03 & -.06 \\
\hline Ethnicity & -.03 & & .03 & -.04 \\
\hline BMI & -.01 & $* *$ & .00 & -.10 \\
\hline Self-Concealment & .05 & & .05 & .15 \\
\hline Psychological Flexibility & .06 & & .05 & .17 \\
\hline Self-Concealment x Gender & -.02 & & .03 & -.13 \\
\hline Psychological Flexibility x Gender & -.04 & & .03 & -.20 \\
\hline
\end{tabular}

Note. ${ }^{*} p<.05,{ }^{* *} p<.01, N=830$ 


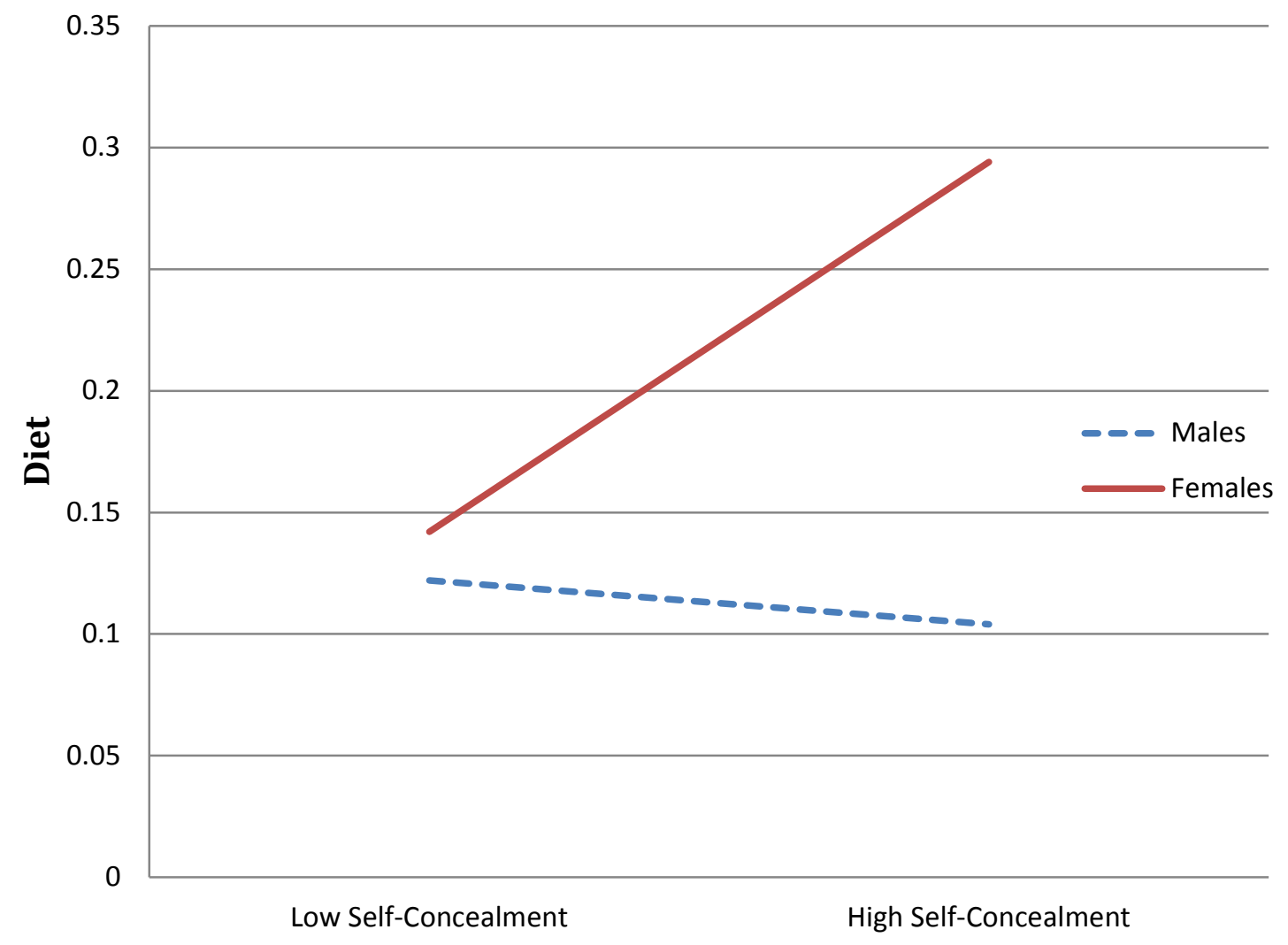

Figure 1. Gender moderates the association between self-concealment and dieting. High and low values of self-concealment correspond to \pm 1 SD from the mean. Dieting scores were long-transformed, $M=.60, \mathrm{SD}=.42$ 


\section{References}

Aiken, L. S., \& West, S. G. (1991). Multiple regression: Testing and interpreting interactions. Thousand Oaks, CA US: Sage Publications, Inc.

Aldao, A., \& Nolen-Hoeksema, S. (2010). Specificity of cognitive emotion regulation strategies: A transdiagnostic examination. Behaviour Research and Therapy, 48(10), 974-983. doi: DOI 10.1016/j.brat.2010.06.002

Aldao, A., Nolen-Hoeksema, S., \& Schweizer, S. (2010). Emotion-regulation strategies across psychopathology: A meta-analytic review. Clinical Psychology Review, 30(2), 217-237. doi: DOI 10.1016/j.cpr.2009.11.004

Berman, M. I., Boutelle, K. N., \& Crow, S. J. (2009). A case series investigating acceptance and commitment therapy as a treatment for previously treated, unremitted patients with anorexia nervosa. European Eating Disorders Review, 17(6), 426-434. doi: 10.1002/erv.962

Bond, F. W., \& Bunce, D. (2003). The Role of Acceptance and Job Control in Mental Health, Job Satisfaction, and Work Performance. Journal of Applied Psychology, 88(6), 1057-1067. doi: 10.1037/0021-9010.88.6.1057

Bond, F. W., Hayes, S. C., Baer, R. A., Carpenter, K. M., Guenole, N., Orcutt, H. K., . . . Zettle, R. D. (2011). Preliminary psychometric properties of the Acceptance and Action Questionnaire-II: A revised measure of psychological inflexibility and experiential avoidance. Behavior Therapy, 42(4), 676-688. doi:

10.1016/j.beth.2011.03.007

Brannan, M. E., \& Petrie, T. A. (2008). Moderators of the body dissatisfaction-eating disorder symptomatology relationship: Replication and extension. Journal of Counseling Psychology, 55(2), 263-275. doi: 10.1037/0022-0167.55.2.263

Cramer, K. M., Gallant, M. D., \& Langlois, M. W. (2005). Self-silencing and depression in women and men: Comparative structural equation models. Personality and Individual Differences, 39(3), 581-592. doi: 10.1016/j.paid.2005.02.012

Fairburn, C. G. (2008). Cognitive behavior therapy and eating disorders. New York, NY US: Guilford Press.

Fairburn, C. G., Cooper, Z., \& Shafran, R. (2003). Cognitive behaviour therapy for eating disorders: A 'transdiagnostic' theory and treatment. Behaviour Research and Therapy, 41(5), 509-528. doi: 10.1016/s0005-7967(02)00088-8

Garner, D. M., Olmsted, M. P., Bohr, Y., \& Garfinkel, P. E. (1982). The Eating Attitudes Test: Psychometric features and clinical correlates. Psychological Medicine: A Journal of Research in Psychiatry and the Allied Sciences, 12(4), 871-878. doi: 10.1017/s0033291700049163

Gross, J. J. (1998). The emerging field of emotion regulation: An integrative review. Review of General Psychology, 2(3), 271-299. doi: 10.1037/1089-2680.2.3.271 
Gross, J. J. (2002). Emotion regulation: Affective, cognitive, and social consequences. Psychophysiology, 39(3), 281-291. doi: 10.1017/s0048577201393198

Hayes, S. C., Follette, V. M., \& Linehan, M. M. (2004). Mindfulness and acceptance: Expanding the cognitive-behavioral tradition. New York, NY US: Guilford Press.

Hayes, S. C., Luoma, J. B., Bond, F. W., Masuda, A., \& Lillis, J. (2006). Acceptance and commitment therapy: Model, processes and outcomes. Behaviour Research and Therapy, 44(1), 1-25. doi: 10.1016/j.brat.2005.06.006

Hayes, S. C., Strosahl, K. D., \& Wilson, K. G. (2012). Acceptance and commitment therapy: The process and practice of mindful change (2nd ed.). New York, NY US: Guilford Press.

Hayes, S. C., Villatte, M., Levin, M., \& Hildebrandt, M. (2011). Open, aware, and active: contextual approaches as an emerging trend in the behavioral and cognitive therapies. Annu Rev Clin Psychol, 7, 141-168. doi: 10.1146/annurev-clinpsy032210-104449

Hudson, J. I., Hiripi, E., Pope, H. G., Jr., \& Kessler, R. C. (2007). The Prevalence and Correlates of Eating Disorders in the National Comorbidity Survey Replication. Biological Psychiatry, 61(3), 348-358. doi: 10.1016/j.biopsych.2006.03.040

Juarascio, A. S., Forman, E. M., \& Herbert, J. D. (2010). Acceptance and commitment therapy versus cognitive therapy for the treatment of comorbid eating pathology. Behavior Modification, 34(2), 175-190. doi: 10.1177/0145445510363472

Kashdan, T. B., \& Rottenberg, J. (2010). Psychological flexibility as a fundamental aspect of health. Clinical Psychology Review, 30(4), 467-480. doi: 10.1016/j.cpr.2010.03.001

Larson, D. G., \& Chastain, R. L. (1990). Self-concealment: Conceptualization, measurement, and health implications. Journal of Social and Clinical Psychology, 9(4), 439-455.

Lavender, J. M., \& Anderson, D. A. (2010). Contribution of emotion regulation difficulties to disordered eating and body dissatisfaction in college men. International Journal of Eating Disorders, 43(4), 352-357.

Lillis, J., Hayes, S. C., \& Levin, M. E. (2011). Binge eating and weight control: The role of experiential avoidance. Behavior Modification, 35(3), 252-264. doi: 10.1177/0145445510397178

Martín-Murcia, F., Díaz, A. J. C., \& Gonzalez, L. P. (2011). A case study of anorexia nervosa and obsessive personality disorder using third-generation behavioral therapies. Clinical Case Studies, 10(3), 198-209. doi: 10.1177/1534650111400899

Masuda, A., Anderson, P. L., \& Sheehan, S. T. (2009). Mindfulness and mental health among African American college students. Complementary Health Practice Review, 14(3), 115-127. doi: 10.1177/1533210110363893

Masuda, A., Anderson, P. L., Wendell, J. W., Chou, Y. Y., Price, M., \& Feinstein, A. B. (2011). Psychological flexibility mediates the relations between self-concealment and negative psychological outcomes. Personality and Individual Differences, 50(2), 243-247. doi: DOI 10.1016/j.paid.2010.09.037

Masuda, A., Boone, M. S., \& Timko, C. A. (2011). The role of psychological flexibility in the relationship between self-concealment and disordered eating symptoms. Eat Behav, 12(2), 131-135. doi: S1471-0153(11)00008-0 [pii] 
10.1016/j.eatbeh.2011.01.007

Masuda, A., Muto, T., Hayes, S. C., \& Lillis, J. (2008). Acceptance and Commitment Therapy: Application to a Japanese client. Japanese Journal of Behavior Therapy, 34, 137-148.

Masuda, A., Price, M., \& Latzman, R. D. (2012). Mindfulness moderates the relationship between disordered eating cognitions and disordered eating behaviors in a nonclinical college sample. Journal of Psychopathology and Behavioral Assessment, 34(1), 107-115. doi: 10.1007/s10862-011-9252-7

Mintz, L. B., \& Betz, N. E. (1988). Prevalence and correlates of eating disordered behaviors among undergraduate women. Journal of Counseling Psychology, 35(4), 463-471. doi: 10.1037/0022-0167.35.4.463

Mintz, L. B., \& Kashubeck, S. (1999). Body image and disordered eating among Asian American and Caucasian college students: An examination of race and gender differences. Psychology of Women Quarterly, 23(4), 781-796. doi: 10.1111/j.1471-6402.1999.tb00397.x

Mizes, J. S., Christiano, B., Madison, J., Post, G., Seime, R., \& Varnado, P. (2000). Development of the Mizes Anorectic Cognitions Questionnaire-Revised: Psychometric properties and factor structure in a large sample of eating disorder patients. International Journal of Eating Disorders, 28(4), 415-421. doi: 10.1002/1098-108x(200012)28:4<415::aid-eat9>3.0.co;2-z

Pearson, A. N., Follette, V. M., \& Hayes, S. C. (2011). A pilot study of acceptance and commitment therapy as a workshop intervention for body dissatisfaction and disordered eating attitudes. Cognitive and Behavioral Practice. doi: 10.1016/j.cbpra.2011.03.001

Pryor, T. L., Johnson, T., Wiederman, M. W., \& Boswell, D. L. (1995). The clinical significance of symptom denial among women with anorexia nervosa: Another disposable myth? Eating Disorders: The Journal of Treatment \& Prevention, 3(4), 293-303. doi: 10.1080/10640269508250059

Rawal, A., Park, R. J., \& Williams, J. M. G. (2010). Rumination, experiential avoidance, and dysfunctional thinking in eating disorders. Behaviour Research and Therapy. doi: 10.1016/j.brat.2010.05.009

Rogers Wood, N. A., \& Petrie, T. A. (2010). Body dissatisfaction, ethnic identity, and disordered eating among African American women. Journal of Counseling Psychology, 57(2), 141-153. doi: 10.1037/a0018922

Slade, P. D. (1982). Towards a functional analysis of anorexia nervosa and bulimia nervosa. British Journal of Clinical Psychology, 21(3), 167-179.

Stice, E., Hayward, C., Cameron, R. P., Killen, J. D., \& Taylor, C. B. (2000). Bodyimage and eating disturbances predict onset of depression among female adolescents: A longitudinal study. Journal of Abnormal Psychology, 109(3), 438444. doi: 10.1037/0021-843x.109.3.438

Striegel-Moore, R. H., \& Bulik, C. M. (2007). Risk factors for eating disorders. American Psychologist, 62(3), 181-198. doi: 10.1037/0003-066x.62.3.181

Tylka, T. L., \& Subich, L. M. (2004). Examining a Multidimensional Model of Eating Disorder Symptomatology Among College Women. Journal of Counseling Psychology, 51(3), 314-328. doi: 10.1037/0022-0167.51.3.314 
Vandereycken, W., \& Van Humbeeck, I. (2008). Denial and concealment of eating disorders: A retrospective survey. European Eating Disorders Review, 16(2), 109114. doi: 10.1002/erv.857

Vohs, K. D., Heatherton, T. F., \& Herrin, M. (2001). Disordered eating and the transition to college: A prospective study. International Journal of Eating Disorders, 29(3), 280-288. doi: 10.1002/eat.1019

Williamson, D. A., Gleaves, D. H., \& Stewart, T. M. (2005). Categorical Versus Dimensional Models of Eating Disorders: An Examination of the Evidence. International Journal of Eating Disorders, 37(1), 1-10. doi: 10.1002/eat.20074

Wonderlich, S. A., Joiner, T. E., Jr., Keel, P. K., Williamson, D. A., \& Crosby, R. D. (2007). Eating disorder diagnoses: Empirical approaches to classification. American Psychologist, 62(3), 167-180. doi: 10.1037/0003-066x.62.3.167 